\title{
Interactions between urban dynamics and new spatial patterns: The case of Istanbul
}

\author{
Hulya Turgut \\ Department of Architecture, Faculty of Architecture and Design, Ozyegin University, Istanbul, Turkey \\ Ozgur Ozten \\ Architect, M. Arch, ITU
}

\begin{abstract}
Cities are increasingly concerned with fluidity and mobility, where social, cultural and economic activities can rapidly be transferred from any one locality to another. Yet, powerful effects of globalisation on economy, society, and urban environment create fragmentation as well as interesting transitions in each system. Whilst urban transformation in response to globalisation creates sharp changes in former urban textures and typologies, new spaces and identities have been produced with the formation of recent networks and encounters. This paper, therefore, examines the implications of urban and housing transformations in the city of Istanbul within the context of recent economic, cultural and political conditions. The authors aim to establish a critical discussion of the city's texture, where separate and overlapping urban functions are easily captured through a site section.
\end{abstract}

Keywords: urban environment, urban transformation, globalisation, housing transformations, city texture

\section{INTRODUCTION}

The rate of change in urban housing environments is continually increasing as the effects of globalisation impact in multiple ways on the contemporary city. Such dynamic processes create what has sometimes been described as a layered construction created over the course of time. Many of the changes relate to the movements and energies of low-income groups whose activities are becoming increasingly dominant in rapidly growing cities throughout the world. There are numerous interrelated factors in the growth of cities. Migrants from rural areas and smallsize cities create pressure on existing urban housing stock and frequently on the development of new informal settlements. Natural growth of urbanised groups leads to large populations seeking affordable accommodation. In some cities, historic or older central areas deteriorate through excessively high densities of tenant populations and, in others, high-density multistorey constructions replace older settlements, changing the social and economic relations of the area. In recent years, especially in metropolitan cities under the umbrella of urban regeneration, informal settlements or deteriorated housing stock have been replaced with high-rise housing and gated communities geared towards the high-income population.

In the case of Istanbul, one of the key factors in the creation of this transformation is the replacement of existing stock (such as informal settlements) with new developments. The new housing stock creates a new chaotic and mixed development which forces different demographic groups to live side by side. Istanbul is a city of layers with a history dating back almost 2,700 years and has served as the capital city for the Roman, Byzantine, Latin and Ottoman empires. Today, with more than 15 million inhabitants, it still preserves the surviving fragments of these civilisations. The city carries significant architectural entities, such as mosques, synagogues, churches, palaces, towers and castles, which represent the various 
chronological layers, serving as the 'modern' face of Turkey's cultural and financial capital. Istanbul has performed as a 'global city' that connects civilisations and continents for several thousand years. In addition to this, it has been facing a new situation caused by new social and spatial urban dynamics. Its urban texture has been changing like any metropolis that is undergoing the trauma of warp speed urbanisation (Figure 1). According to the international investigation of cities carried out by the Urban Age Project, Istanbul may not be growing at the dizzying pace of Mumbai and Shanghai, nor suffer from the widening social inequality and violence of São Paulo, Mexico City or Johannesburg, but it does face many of the same challenges confronted by all 'Urban Age' cities, including London, Berlin and New York: economic stability, social cohesion and climate change (Burdett \& Nowak, 2009).

Turkey's urbanisation started to accelerate in the 1950s. Due to the lack of housing policies and inefficiency in providing housing to the newcomers, the city experienced the gecekon$d u s$, which are basic shelters for low-income inhabitants. Later, this phenomenon shifted into apartkondus, where the gecekondus were transformed into apartment blocks. The authorities applied little restriction over this process of newly built illegal settlements on public land, both in terms of quantity and quality. Therefore Istanbul, along with many other big cities, faced urban margins with no infrastructure, public space and legal status. In the 1980s, along with continuing economic development and reforms, these formerly prestigious innercity districts gained new popularity among higher-income families, attracted by their location close to the financial district (Ergun, 2004). Most of the physical transformation associated with globalisation has taken place with the development of gated communities and five-star hotels. Istanbul has been packaged as a consumption artefact for tourists and new office towers, with the expulsion of small businesses from the central districts, gentrification of the old neighbourhoods, and global images on billboards and shop windows (Oncu, 1997). In the last four decades, Istanbul's sociocultural and urban identities have been undergoing radical transformation. Although Istanbul has always been a city of duality, fragmentation and polarity, it has never before displayed such intense qualities of heterogeneity as it does today (Keyder, 1999). Economic policies seem to have always had a strong effect on urban growth and change in Turkey. In each period, the urban space has been shaped by the economic policies of the state. As in other countries, social and cultural change in Turkey has followed economic cycles. While today's cities are being shaped within the effect of global restructuring processes, urban housing has been evolving by itself, interacting with these changes. The development of housing areas and the creation of the environment are therefore being formed under the influence of a confused interaction between globalisation and the city's own history (Turgut, 2010).

In this context, this paper is based on ongoing research on 'new urban housing concepts' and the Master's thesis of Ozgur Ozten, supervised by Hulya Turgut (Ozten, 2010). The ongoing research seeks to examine various examples of new housing developments in Istanbul by investigating the social and spatial dynamics of its new situation. This provides and creates a platform to discuss the issues of emerging residential patterns and dynamics of the city of Istanbul.
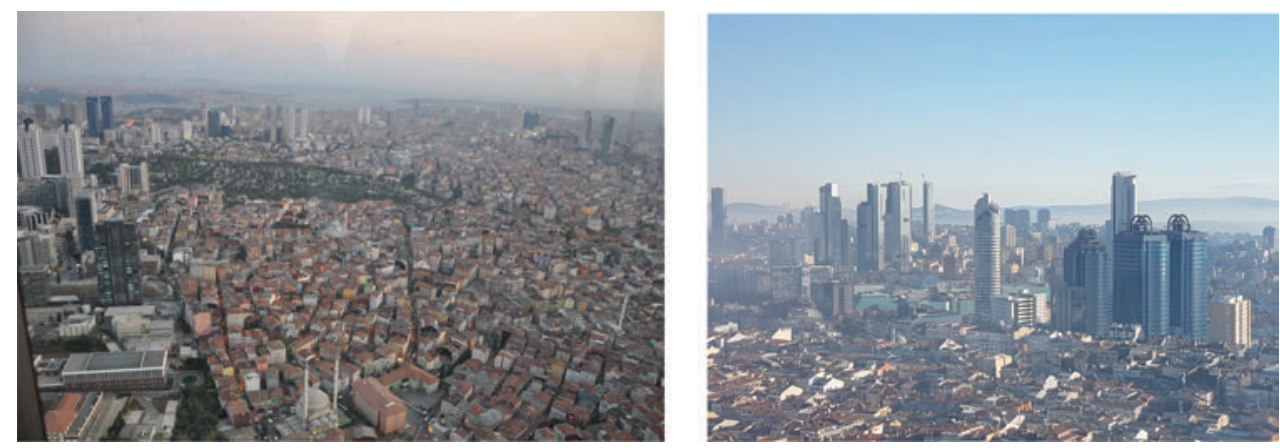

Figure 1. New faces of the city profile of Istanbul. 


\section{URBAN DYNAMICS AND NEW RESIDENTIAL PATTERNS EMERGING IN ISTANBUL}

Today's urban dynamics follow changes in global restructuring processes and cities are becoming the stages for transformation. The urban dynamics that arise from global platforms also have an effect on the formation of new urban housing trends. Between the city and its role in the process of globalisation, there is a transactional relationship which arises from economic, political, sociocultural and technological changes. Urban dynamics that affect the transformation can be categorised into six main areas: global economy; being a 'world city'; diversification; new joint ventures and participation; new industries; social exclusion and societal fragmentation (Cakır, 2007; Turgut, 2010; Turgut \& Inalhan, 2007). The concept of the global economy brings prestige, competition, economic revival, governance and foreign capital. Thus, by the expansion of the global economy, urban transformations are targeting the 'marketing of place and prestige'. The representational need of the city in this matter gives rise to the concept of a world city in terms of urban identity, image, environmental quality, tourism, consumption and the industry of culture. The focus on urban identity, image and quality also has a direct relationship with urban memory, sustainability, local culture and conservation as components of diversification. The generation of knowledge, advanced technologies and productivity as the dynamics of new industry in the city has an impact on urban transformation. All these interlinked urban dynamics also highlight issues of social exclusion and fragmentation, where the need to bring equality, liveability and accessibility is the aim of an urban transformation. All of these concepts have found their reflections in the formation of a holistic urban vision (Turgut, 2010).

Istanbul's rapid urban transformation during the economic restructuring process of the last four decades has occurred through the interaction of politics, culture and economy, and been directed and legitimised by the global city discourse. During this period, many global city discourses have been developed for Istanbul. Central government and local authorities have proposed various projects to position Istanbul as a global city. These projects have been radically transforming Istanbul's urban identity and the city has been growing with intense heterogeneity, especially in its urban housing (Turgut, 2010). Since the beginning of the 1980 s, change in the city has been the driven by the effects of globalisation, liberalisation of the economy, rapid urbanisation and technological advances. This change, while being more prominent in the 1980s, gained momentum in the 1990s. Economic policy, which produced radical changes in the social structure, played a key role in the change and transformation process. It transformed the urban space and created new urban forms.

In the mid-1980s, the peripheries of Istanbul became more popular for residential settlements for the urban middle-high and high-income groups. In the 2000s, inner-city residential areas became affordable and desirable for middle-income groups. According to Kurtuluş (2005), the reason for the security tendency in the case of Istanbul is the urban elites trying to integrate the global consumption culture in their residential areas. Prestigious neighbourhoods guarantee real estate values, security and a sense of privilege and there are, therefore, often gated settlements in Istanbul. Developments caused by changing economic structure and global influences have created a new metropolitan lifestyle for the middle- and upperincome groups, which has resulted in a demand for luxurious new houses. The development of new housing patterns over the last 30 years in Istanbul can be divided into four categories: garden cities - suburbia (beginning in the 1980s): luxurious housing - villa towns and settlements (beginning in the 1980s); multi-storey residences (beginning in the 1990s); mixed city housing (beginning in the 2000s); and mixed inner-city and outer-city housing (Turgut, 2010; Turgut et al., 2010).

In this context and over the last four decades in Istanbul, the urban texture represents different elements of choices, time periods, styles, functions and users with an intense degree of heterogeneity. At this point, the urban section of the city is capable of forming a new type of urban layout: a mixed form of functions and transformations. In order to show this new type of mixed urban layout, this paper will analyse a cross section of the Levent-Maslak neighbourhood in Istanbul, with a focus on housing developments. 


\section{ISTANBUL'S CHANGING URBAN TEXTURE: THE EXAMPLE OF THE LEVENT-MASLAK AXIS}

As already described, the new forms of housing area resulting from the effects of the interactions between globalisation and the city's own history give Istanbul several important urban areas to exemplify this structure. The Levent-Maslak axis in Istanbul is an important example in exposing the changing urban texture and housing preferences. It is more of a critical debate about the area of focus where the social and physical fragmentation are clearly exposed. By analysing this part of the city, this paper aims to cover the accessibility and the readability of the different dynamics of the urban environment and their reflections on the process of transformation. Therefore, through the changes in the Levent-Maslak area in economic, political, social, ecological and psychological terms, contradictions, transformations and reproductions are combined within the same location and can be exposed.

The Levent-Maslak axis has an important and critical function as the node point between the Asian and European routes of the city's main roads. Therefore, it is the most important north-south transportation axis within the city.

The Levent-Maslak axis named Büyükdere Street started a change in its development path during the 1990s with the rapid construction of high-rise buildings, increasing rates of highdensity population, and a shift in profile. The axis is shown in Figure 2: on the west side the street covers the illegally developed neighbourhoods of Ortabayir, Celiktepe and Emniyet Evleri, and on the east side Levent and Konaklar neighbourhoods exist with a shift in their previous functions of being social housing units into mostly business and commercial use (Ozten, 2010). This differentiated development of the axis, therefore, has brought an emerging sociocultural fragmentation, duality, polarity, social exclusion, especially since the 1990s. For a resident of the city, the social exclusion process is becoming more evident via spatial diversification. While holding a spatial sense of belonging towards a location, an exclusion
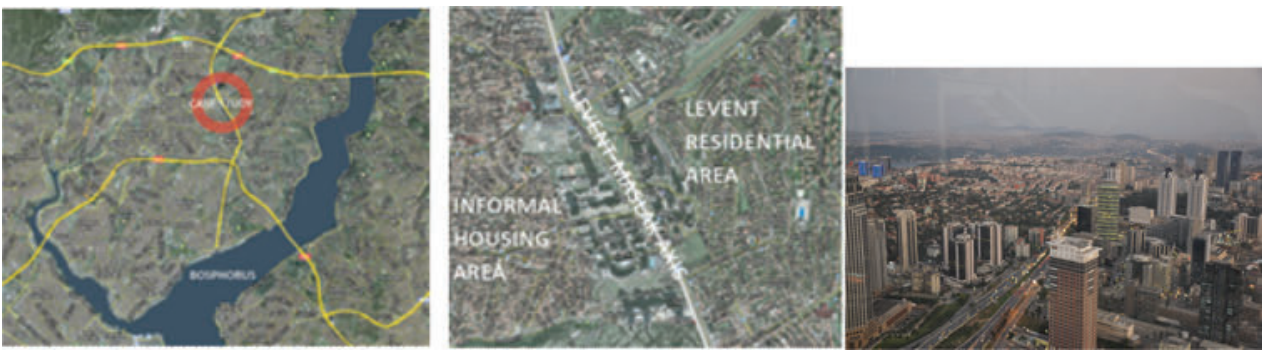

Figure 2. Location of the Levent-Maslak axis and its close surroundings.

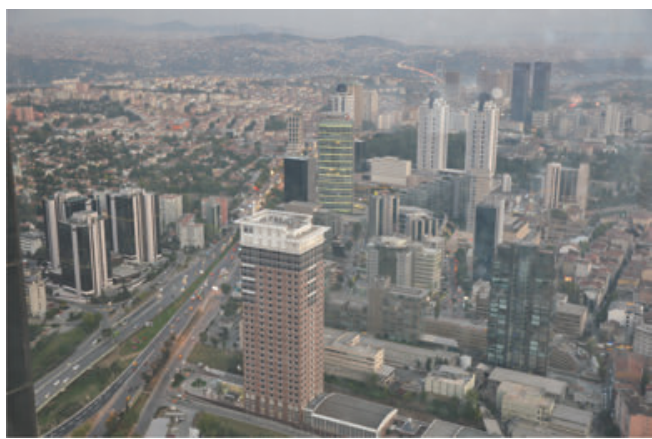

Figure 3. Levent high-rise blocks and the Levent's former social housing units on the left, and illegal housing areas on the right. 
from all the other elements brings social exclusion and cultural and spatial fragmentation. These developments result in a mix of identities or, in a general context, the loss of the identity of the city itself (Kurtuluş, 2005).

In this framework, the focus on the Levent-Maslak development axis and its cross section aims to expose the loss of identity of the city where social and spatial fragmentation is sharp and sense of belonging is relative. The aim is to create a critical framework for the process of rapid urbanisation of the city of Istanbul and its impacts on the city's different housing areas and preferences. Therefore, urban development phases through the cross section of the Levent-Maslak axis will be described within the time frame in order to pin down key points of spatial and social transformation and fragmentation.

\subsection{Formal part of the axis: Levent social housing area}

The area was designated as the northern development path of Beyoglu district and proposed to become a housing settlement. It started to develop in 1947 with the social housing project of Emlak Kredi Bank, completed in 1960 as one of the few exemplary social housing projects of the Turkish Republic. In 1975, single-storey housing units were given permission for a plus one storey and this permission brought the settlement a spatial change. With the 1980s master plan for the metropolitan area, Levent was assigned as a housing development site to promote Istanbul's importance and image within the global arena. According to the 1994 master plan, due to the increased efficiency of highway and transportation axes, the commercial axis of the 1980s master plan was expanded towards the Maslak area in the west. After the construction of the second bridge over the Bosphorus, the joint roads cut through the Levent area and, together with this effect of transportation, the neighbourhood started to be impacted by a second transformation phase. This transformation mainly triggered functional changes as well as an increase in market values. This sharp differentiation in values brought social housing into a luxurious housing development and this change was reflected spatially on site, especially with the Besiktas Municipality's permission in 1991 for preservation of heights of the units, transformation of buildings to tourism-oriented commercial units (Ozten, 2010).

\subsection{Informal settlement areas: Ortabayir, Celiktepe and Emniyet Evleri}

While the Levent social housing development started its implementation, the west side of this location was being used for agriculture and animal farming in the 1950s. Because of the rapid

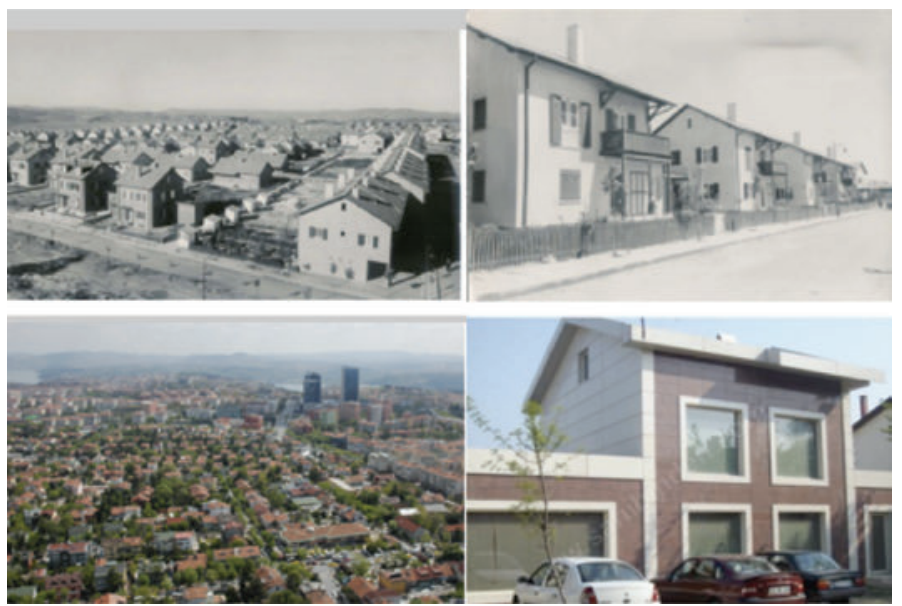

Figure 4. Former and current social housing of Levent on east side of the Levent-Maslak axis (Aru \& Gorbon, 1952). 

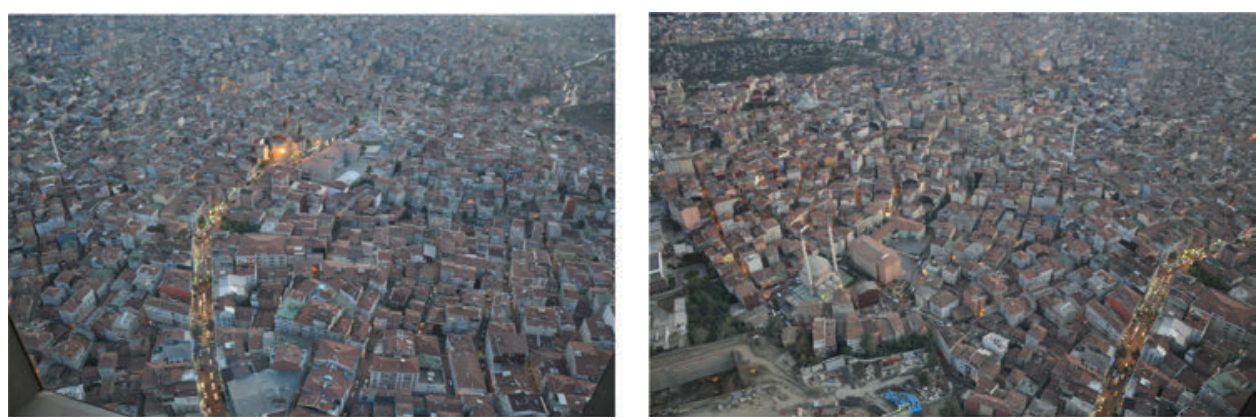

Figure 5. Informal settlement areas: Celiktepe neighbourhood on west side of the Levent-Maslak axis.

migration process from rural to urban areas, at the end of the 1950s these locations- known today as the neighbourhoods of Ortabayir, Celiktepe and Emniyet Evleri-were given to immigrants by the municipality in order to cover the increased need for housing. This was followed by the development of unplanned and illegally built housing units in the area. With the first master plan implementation in 1975 and the permissions given to illegal developments between 1975 and 1985 the spatial texture of this area started changing. With 1985's rehabilitation master plan, the transformation process of low-storey housing units brought medium-sized apartment blocks to the site and the characteristics of the illegally developed settlement were continuously changed (Ozten, 2010). From this period onwards, it is possible to locate spatial formations belonging to different development processes of the area.

\subsection{Büyükdere Street as the Levent-Maslak axis}

According to the Prost master plan (1937) for Istanbul, all roads towards the north were supposed to be enlarged in order to create a main artery. With the additional planning of 1955 and the development of a new industrial area in the Levent neighbourhood, low-cost lands in the surrounding area started to develop illegally on the west side, whilst along the road industrial buildings and factories started to get built. From the 1970s, the Levent-Maslak axis was developed along with new urban developments in the city. It is important due to its northerly direction towards water reserves and forests. In the 1980s, office buildings started to get constructed along the road. Besides its orientation towards the north, Büyükdere Street is today used as a prestigious business centre that is different from neighbouring areas. Since the 1990s, the functions along the street have shifted greatly towards business, residences, shopping, commerce and offices (Gulen, 2006). The street is now a mixed-use, high-rise axis of the city of Istanbul (Ozten, 2010).

\subsection{Evaluation}

Istanbul as a multifaceted metropolis has gone through a rapid transformation process as a result of local and global pressures. During the 1980s, effects and transformations on the spatial environment became sharp and dynamic. In this context, two main approaches were exposed in the city's development. The first one was, as Ohmae (1995) states, that the world moved towards a singular identity and lost regional constitutions, and the other approach was, as Taylor (2000) underlines, that the global economy created new spatial forms as well as controlling the surroundings. In this response to the new millennium, spatial developments started to be more competitive in order to attract large-scale projects and foreign capital. In this manner, cities such as Istanbul sought to boost their urban environments and their popularity by adapting themselves to the new global urban dynamics.

In this context, this paper aims through the case study to visualise a dynamic spatial development during the last 60 years of the city's development history. Thus, the impacts of all the periodical urban and social dynamics are exposed within a cross section of the 
Levent-Maslak axis and its surroundings (see Figure 6). Together with a clear distinction between the fragmented social and spatial characteristics of the neighbourhoods, Büyükdere Street has developed as a catalyst of the global dynamics for the whole area in terms of construction and spatial transformation. Therefore, because of the force exerted by the new type of urban development that fits into the global dynamics, the close surroundings of the street were affected by this influence much more radically. Thus, through a time frame bulleting the differentiation of urban dynamics according to the current needs and expectations, an urban development path is exposed. With the transformation of planning visions and political assents, a sharp change in the social and spatial developments brought fragmented societies and spaces into the cityscapes in return. In this manner among the city of Istanbul's sharp transformation process through local policies since 1940s, sharp changes in the urban identity and the image, social and spatial texture are being exposed for the case study area of the Levent-Maslak axis in this paper. In the 1940s, along with the start of rapid migration and the process of industrialisation, Istanbul, just like many big cities, also faced rapid urban development and new formations in its spatial texture. New urban development plans and implementations also catalysed the formation of the new avenues of Vatan and Millet, new factories and industries in the Levent area, and neighbourhoods like the Levent social housing settlement. As a result of these new developments, the lack of housing policies, insufficient housing for newcomers, and the destruction of housing areas to open up new avenues, the Istanbul municipality gave the Ortabayir, Emniyet Evleri and Celiktepe areas, which were former agricultural lands of Kagithane village, to the immigrants to settle. On the other hand, with the modernisation period of the country, Levent social houses were also built between 1947 and 1958 in order to exemplify a modern neighbourhood development. In this context, the rapid housing developments of the city varied from horizontally growing illegal settlements to new neighbourhood designs of social houses according to modern theories. From the 1960s onwards, urbanisation within the city speeded up and enforced the Levent-Maslak axis as a new urban route, together with its modern housing and industry. Emphasis on motorways and highway transportation also sped up the development of the Levent-Maslak axis. With the opening of the first bridge over the Bosphorus in 1973 and the second one in 1988, the Levent-Maslak axis became a joint venture in the area. Increase in the commercial and industrial developments along the axis catalysed the extension of the illegal settlements around Emniyet Evleri, Ortabayir and Celiktepe neighbourhoods and increased the horizontal and vertical growth in these areas.

With 1980s neo-liberal influences, Istanbul started to become a metropolis and created a vision to establish a modern image within the global arena. One of the peak points in this period is the start of permissions for illegally developed areas, which led to a situation in which horizontal and low-rise housing grew towards medium-sized apartment blocks. The process started the transformation of housing settlements physically as well as functionally. With the new visionary developments of the city, the Levent-Maslak axis started to reshape
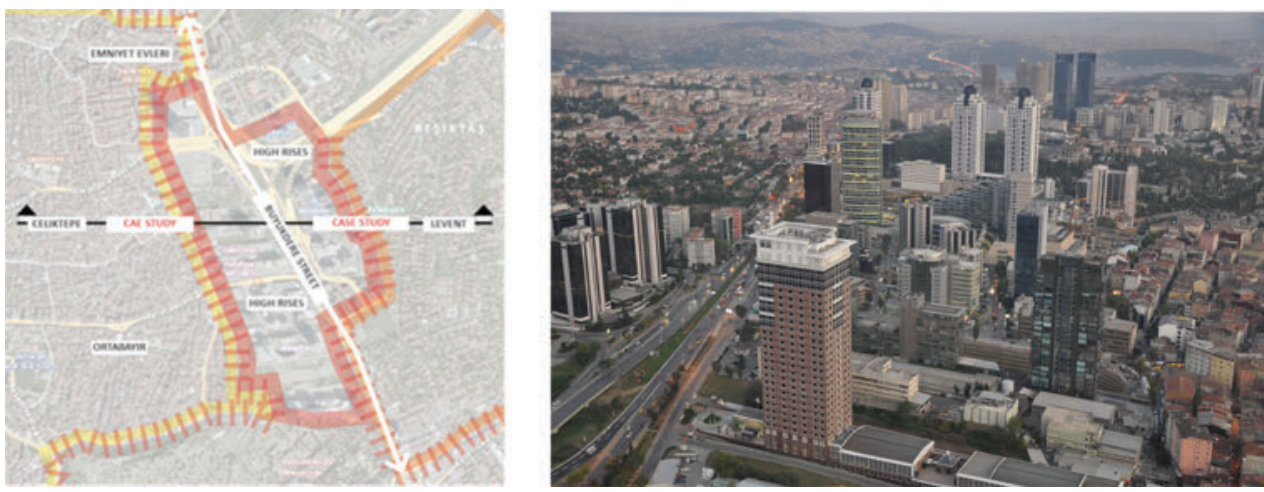

Figure 6. Interaction zones within the focal section of the case study area. 
its first structure and moved towards commercial and housing in mixed use. From the 1980s until the millennium, fluid and rapid global influences developed the Levent area as an image of the city of Istanbul with its modern housing, and recently implemented commercial uses. By the 1990s, the Levent-Maslak axis had become the modern representative of business and commerce with the first high-rise constructions in the city of Istanbul.

In the last two decades, through the significant effects of the global economy and the political pushes for Istanbul to become a world city, a construction peak has taken place along the Levent-Maslak axis. This construction boom affected the former spatial texture and demonstrates a dynamic transformation process in the case study area. In this respect, along with the axis as the main centre of gravity for the zone, the adjacent, illegally developed neighbourhoods of Emniyet Evleri, Ortabayir and Celiktepe, as well as the Levent social housing area, have adapted their physical environments and sociocultural inputs to the recent global dynamics.

In this manner, the urban transformation of the area exposes a social and spatial fragmentation, with a societal exclusion along the main axis. Thus, although a sharp distinction along the axis exists in physical, social, cultural and economic terms, fragmentation among the society within the area creates a contested heterogeneity. Therefore, across the area as a whole it is possible to expose a variety of physical examples of different periods that developed due to changing urban dynamics. To sum up, from 1940s until today, development of the LeventMaslak axis has created an urban contest due to global dynamics reflected in the site. This urban contest eventually affected the housing settlements in the area and resulted in socially and spatially fragmented urban development.

\section{CONCLUSION}

The paper concludes its urban development statements for the city of Istanbul, where recent urban dynamics are restructuring the cityscape and the society in physical, social and cultural terms. Based on this framework, recent housing projects, new development trends, former urban patterns and new forms of spatial and sociocultural interactions are reflected in the city's development attitudes and its future development. However, it is also important to underline that the interaction of spatial dynamics, sociocultural values, and their transitions give rise to a rapidly changing urban settlement. In addition to this dynamic movement, a loss of cultural, social and spatial identity takes place through the effects of globalisation. Particularly since the neo-liberal urban dynamics of the 1980s, globalisation has created spatial and social tensions, emphasis on real estate values, and representational struggles for creation of a holistic image.

As a multi-layered or palimpsest city, Istanbul, with its historical and cultural values, undergoes an important and rapid transformation process. The importance of the transformation process of the city is its intense speed. In fact, the speed of the process shifted the urban texture of the city from a small-scale contractor, small-sized plot combination of little architectural input to a high-level social class's market development.

Cities do face continuous changes; however, within this continuous change some manage to transform spaces through development of their unique characteristics. In the case of Istanbul, rapid change of the cityscape has brought little quality into the spatial texture but rather a mixture of interaction and a loss of identity. Today, Istanbul might be characterised as a city based on a multilayered physical structure of a variety of influences and contradictions from Eastern and Western civilisations. However, as a city that faces migration, and constant reshaping over the past 2,700 years, this historical, spatial and sociocultural palimpsest within the urban environment should be analysed with a multi-dimensional and comprehensive approach and accepted as a heterogeneous compound.

To develop a visionary approach for the heterogeneous structure of the city of Istanbul, in which new dialogues and alternative development strategies can facilitate the establishment of social and spatial links, a holistic approach is needed. Thus the formation of spatial environments, housing settlements, representative spaces whilst developing qualified environments 
for inhabitants of the city, the potential of palimpsests and heterogeneity of spaces should develop inclusive urban environments as well as social interaction.

\section{REFERENCES}

Aru, K.A. \& Gorbon, R. (1952). Levent mahallesi. Arkitekt, 253-254, pp: 167-173.

Burdett, R. \& Nowak, W. (2009). Istanbul: City of intersections. London, UK: Urban Age.

Çakir, N. (2007). Impacts of current urban dynamics on urban transformation (Master's thesis, Istanbul Technical University, Institute of Science, İstanbul, Turkey).

Ergun, N. (2004). Gentrification in Istanbul. Cities, 21(5), 391-405.

Gulen, M. (2006). "Stratejik planlama yaklasimi cercevesinde kentsel projeler-Kamusal alan iliskisi: Buyukdere aksi levent plazalar alani ornegi"/Urban projects in the context of strategic planning approach - Public space relation: the example of Buyukdere-levent axis (Master's thesis, Mimar Sinan Fine Arts University, Istanbul, Turkey).

Keyder, C. (1999). Istanbul: Between the global and the local. Lanham, MD: Rowman \& Littlefield.

Kurtuluş, H. (2005). Garden City as an Utopia/Bir utopya olarak bahçeşehir. In H. Kurtuluş (Ed.), Istanbulda kentsel ayrışsa/Urban Fragmentation in Istanbul Istanbul, Turkey: Baglam yayıncilık.

Ohmae, K. (1995). The end of the nation state: The rise of regional economies. London, UK: Simon \& Schuster.

Oncu, A. (1997). The myth of the 'ideal home' travels across cultural borders to Istanbul. In A. Oncu \& P. Weyland (Eds.), Space, culture and power: The new identities in globalizing cities (pp. 56-72). London, UK: Zed Books.

Ozten, O. (2010). Evolution of everyday life by place and in place: the structure of the processes of change of cities: Levent - celiktepe example Gündelik hayatın mekânla vee mekânda evrilmesi, kentlerin degisim süreçlerinin yapılandırmast: Levent—celiktepe örneği (Master's thesis, Istanbul Technical University, Institute of Science, Istanbul, Turkey).

Taylor, P. (2000). World cities and territorial states under conditions of contemporary globalization. Political Geography, 5, 19-32.

Turgut, H. (2010). Urban dynamics and transformations and their impact on urban housing: The case of Istanbul. Open-House International, 35(4), 76-84.

Turgut, H. \& Inalhan, G. (2007). Cultural and spatial dynamics of Istanbul: New housing trends. Paper presented at ENHR 2007, International Conference-Sustainable Urban Areas, Rotterdam, The Netherlands.

Turgut, H., Yönet, A.N. \& Torus, B. (2010). Global dynamics and new residential developments in Istanbul: Trends and expectations. In L. Villegas, O. Ural, V. Abrantes, I. Lombillo \& C. Liaño (Eds.), Design, technology, refurbishment and management of buildings, 37th IAHS World Congress on Housing Science, Santander, Spain. 